\title{
The Role of Physician and Practice Characteristics in the Quality of Diabetes Management in Primary Care: Systematic Review and Meta-analysis
}

\author{
F. Riordan, $P h D^{7}$ (D) S. M. McHugh, $P h D^{7}$, Clodagh O'Donovan', \\ Mavis N. Mtshede, $\mathrm{MPH}^{7}$, and P. M. Kearney, $P h D^{7}$ \\ 'School of Public Health, University College Cork, Cork, Ireland; ${ }^{2}$ School of Medicine, University College Cork, Cork, Ireland.
}

\begin{abstract}
BACKGROUND: Despite evidence-based guidelines, highquality diabetes care is not always achieved. Identifying factors associated with the quality of management in primary care may inform service improvements, facilitating the tailoring of quality improvement interventions to practice needs and resources.
\end{abstract}

METHODS: We searched MEDLINE, EMBASE, CINAHL and Web of Science from January 1990 to March 2019. Eligible studies were cohort studies, cross-sectional studies and randomised controlled trials (baseline data) conducted among adults with diabetes, which examined the relationship between any physician and/or practice factors and any objective measure(s) of quality. Studies which examined patient factors only were ineligible. Where possible, data were pooled using random-effects meta-analysis.

RESULTS: In total, 82 studies were included. The range of individual quality measures and the construction of composite measures varied considerably. Female physicians compared with males ((odds ratio $(\mathrm{OR})=1.07,95 \%$ CI: 1.04, 1.10), 8 studies), physicians with higher diabetes volume compared with lower volume $(\mathrm{OR}=1.24,95 \% \mathrm{CI}$ : 1.05-1.47, 4 studies) and practices with Electronic Health Records (EHR) versus practices without $(\mathrm{OR}=1.43,95 \%$ CI: $1.11-1.84,4$ studies) were associated with a higher quality of care. There was no association between physician experience, practice location and type of practice and quality. Based on the narrative synthesis, increasing physician age and higher practice socio-economic deprivation may be associated with lower quality of care.

DISCUSSION: Identification of physician- and practicelevel factors associated with the quality of care (female gender, younger age, physician-level diabetes volume, practice deprivation and EHR use) may explain differences across practices and physicians, provide potential targets for quality improvement interventions and indicate which practices need specific supports to deliver improvements in diabetes care.

KEY WORDS: diabetes; quality of care; primary care.

Electronic supplementary material The online version of this article (https://doi.org/10.1007/s11606-020-05676-7) contains supplementary material, which is available to authorized users.

Received August 29, 2019

Revised December 3, 2019

Accepted January 19, 2020

Published online February 3, 2020
J Gen Intern Med 35(6): 1836-48

DOI: $10.1007 / \mathrm{s} 11606-020-05676-7$

(c) Society of General Internal Medicine 2020

\section{INTRODUCTION}

Routine management of diabetes is increasingly delivered in primary care where patients can receive care closer to home. ${ }^{1,2}$ Despite the abundance of guidelines, ${ }^{3-5}$ high quality of care is not always achieved; risk factor control continues to be suboptimal, ${ }^{6}$

11 with international variation in the achievement of clinical targets. ${ }^{7}$ Interventions to improve diabetes management are not always successful, with limited impact on clinical outcomes. ${ }^{12,13}$

Understanding how to close this 'evidence to practice gap, ${ }^{14,}, 15$ and successfully introduce and embed evidencebased care into real-life practice, is central to the delivery of effective, appropriate and safer clinical care. ${ }^{14}$ Primary care is a challenging setting in which to deliver evidence-based care. Managing complex and potentially co-morbid ${ }^{16}$ patients with chronic diseases such as diabetes, requires physicians to cope with competing priorities ${ }^{17}$ and time constraints ${ }^{18}$, compounded by workforce shortages. ${ }^{19-25}$ Identifying what factors influence the quality of diabetes management in primary care may inform strategies to improve adherence to evidencebased care and tailor quality improvement (QI) interventions to the real-life context. ${ }^{26}$ This systematic review assembles existing evidence on relationship between primary care factors and measures of quality of diabetes care to (1) explore variation in quality across practices or physicians and (2) to determine practice and physician factors which contribute to the 'evidence to practice' gap.

\section{METHODS}

We conducted and reported the review in accordance with PRISMA (Preferred Reporting Items for Systematic reviews and Meta-Analyses) statement ${ }^{27}$ and the published protocol. ${ }^{28}$

\section{Eligibility Criteria}

Eligible studies were cohort studies, cross-sectional studies and baseline data from randomised controlled trials (RCTs) 
conducted among adults aged $\geq 18$ years with diabetes (type 1 or type 2), which examined the association between physician and/or practice factors and quality of care. We excluded studies if they only examined patient factors. A preliminary search of the literature identified a priori physician and practice factors. Where we identified studies which examined other practice factors, we included them if the factors could be classified according to four out of five categories of the Cochrane Effective Practice and Organisation of Care (EPOC) 'Delivery Arrangements' domain ${ }^{29}$ (see further eligibility details in Supplement 1).

The primary outcome of interest, quality of diabetes care, was a broad construct comprising of either individual objective measures of quality; performance of care processes or control of intermediate clinical outcomes (e.g. BP, cholesterol, HbAlc), screening for complications or attendance at screening services, prescribing of appropriate medications, treatment inertia or intensification or a composite of individual measures. Patient-reported outcomes, including functional status, health-related quality of life, satisfaction with treatment and treatment adherence were secondary outcomes. As quality of care should ideally be based on a range or composite of different measures ${ }^{30,31}$ rather than a single measure such as $\mathrm{HbAlc}^{32,}{ }^{33}$, the review focused on studies examining multiple and/or composite measures of quality. Studies which examined only one individual quality measure were excluded.

\section{Identification and Selection of Studies}

We conducted literature searches of MEDLINE, EMBASE, CINAHL and Web of Science for studies conducted between January 1990 and March 2019, and published in English, which examined the association between physician and/or practice-level factors and quality of diabetes care in primary care. We searched databases using Medical subject headings (MeSH) and keywords for (1) diabetes; (2) primary care; (3) practice or physician factors, broad (e.g. 'practice characteristics') or specific (e.g. 'gender', 'experience') terms; and (4) quality of care (see EMBASE strategy in Supplement 1). Reference lists of included studies were screened. Search results and fulltext articles were independently assessed by two reviewers (FR and COD). Disagreements were resolved through consensus or referral to a third reviewer.

\section{Data Extraction and Quality Assessment}

Using a standard form, FR extracted data on study design, region, sample size, patient and physician characteristics and quality measure(s). Authors were contacted for additional data if required. Study quality was assessed (by FR) using the modified Joanna Briggs Institute critical appraisal checklists for descriptive studies. ${ }^{34}$ Articles were not excluded from the review based on the quality assessment.

\section{Synthesis}

We conducted a meta-analysis where at least two studies examined a comparable individual or composite quality measure. In general, studies were not included in a meta-analysis if the data were unavailable, exposure or outcome variables were not comparable, there was no adjustment for confounders, or if a continuous outcome variable was measured but data were unavailable to calculate the standardised mean difference (SMD). Studies which could not be included in a metaanalysis were included in a narrative synthesis. We conducted random-effects meta-analyses of the adjusted effect estimates using the inverse variance method in RevMan 5.3 (Nordic Cochrane Centre). Where unavailable from the article or study authors, 95\% CIs and/or standard errors (SE) were calculated from the effect estimate and $p$ value. ${ }^{35,36}$ Forest plots were used to visually assess the estimates and corresponding CIs across studies. Statistical heterogeneity was assessed with the $I^{2}$ statistic. Forest plots are presented with and without pooled effects. We highlight where analyses indicated significant heterogeneity $\left(I^{2}>60 \%\right)$.

\section{RESULTS}

From 7198 records, 78 were retained (Fig. 1), and four were identified from reference lists. Most studies were from the US $(n=38)$ or UK $(n=18)$ (Suppl.Table 1). Sample size varied considerably from smaller local studies ${ }^{37}$ to large-scale national studies. ${ }^{38}$ Some studies focused on specific sub-groups, e.g. Medicare beneficiaries ( $\geq 65$ years), ${ }^{37,}, 39-42$ or patients with type 2 diabetes. ${ }^{37,}{ }^{43-54}$ Most studies involved a mix of private/public centres ${ }^{41}, 49,50,55-60$ and academic/non-academic $^{43,58}$ and teaching/non-teaching practices. ${ }^{44,54,61-67}$ Included studies examined individual $(n=41)$, composite $(n=24)$ or both $(n=11)$ quality measures. Seven examined treatment intensification or inertia. Individual indicators used to construct composite measures ranged from four process measures ${ }^{68,69}$ to 18 process and outcome indicators from the Quality and Outcomes Framework (QOF) ${ }^{44,}$ 68, 70, 71 (Suppl. Table 2).

Frequent individual measures ( $>20$ studies) were $\mathrm{HbAlc}$ testing $(n=34)$, eye examination or referral to ophthalmology $(n=31)$, lipid testing $(n=30)$ and HbAlc level/target $(n=27)$ (see Suppl. Tables 3-5 for a detailed overview). Three physician factors (gender, experience and diabetes volume) and practice factors (location, type and presence of an EHR) were included in the meta-analyses.

Some studies did not adjust for confounders $(n=11)^{37-39}$, $65,72-78$, examine patient-level factors or include them as covariates $(n=33)^{37,38,40,41,44,46,47,57,61,63-65,67,68,70-}$ 76, 78-89 (Suppl. Table 6). Where general practice data were used to determine outcomes, few explained the data abstraction process, ${ }^{58,60,64,74,84,90-95}$ or cited the reliability. ${ }^{44,50,55 \text {, }}$ 60, 70, 84, 90, 92, 94, 95 In some studies, exposure ascertainment ${ }^{42}$, $50,51,65,70,76,83,91,96-99$ and inclusion criteria for practices 


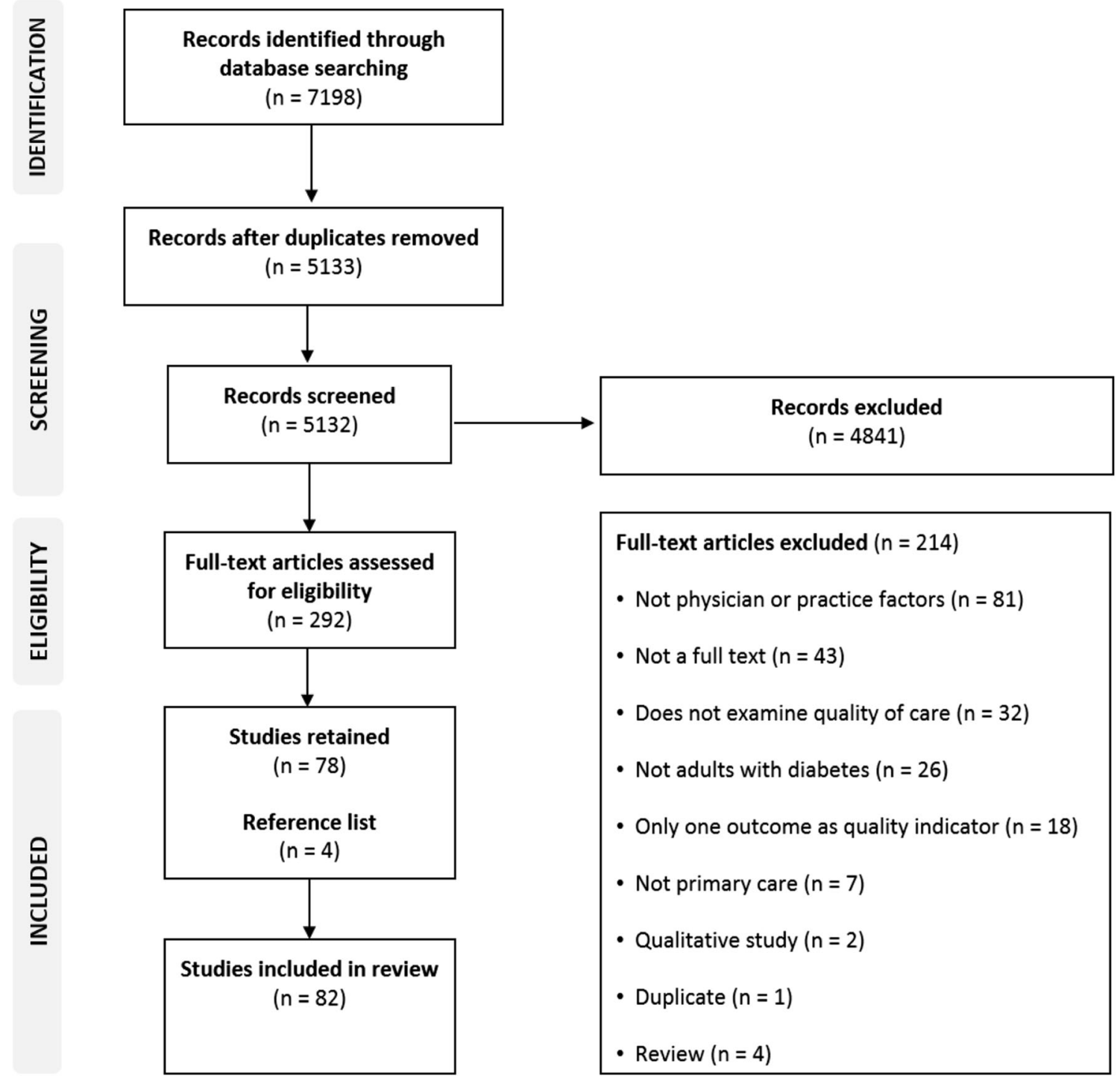

Fig. 1 Flow diagram showing the study selection process for the current review.

and/or physicians $52,56,60,64,65,67,75-77,80,83,84,89,100,101$ were unclear or not reported. Two studies used volunteer practices. $^{43,102}$ Reporting of the total number of practices, physicians or patients, was inconsistent.

\section{PHYSICIAN FACTORS}

\section{Gender}

Individual Measures. Twenty-one studies examined gender. ${ }^{43}$, 47-49, 51, 53, 57, 69, 80, 81, 91, 92, 99, 103-110 Thirteen studies used individual outcome measures. ${ }^{43}, 47-49,51,91,92,99,104-109$, nine of which $^{48,91,104-110}$ were included in a meta-analysis. Overall, female gender was associated with higher quality of care (any individual measure) $(\mathrm{OR}=1.07,95 \% \mathrm{CI}: 1.04-1.10)$ (Fig. 2). There was substantial statistical heterogeneity $\left(I^{2}=79 \%\right)$. Of the seven studies examining individual measures which could not be included in the meta-analysis $43,47,49,51,92,9953$, four found no association, ${ }^{43,47,51,99}$ while two found that among female physicians, quality was higher ${ }^{49,}, 92$ or reported mixed results. ${ }^{53}$

Composite Measures. The seven studies using a composite measure $^{57,69,80,81,103,104,108}$ could not be pooled. Four ${ }^{80,81 \text {, }}$ 103,108 reported no significant association, while three ${ }^{57,69,104}$ found an association between female gender and higher quality.

\section{Professional Experience}

Individual Measures. Eight studies defined experience as years since graduation ${ }^{80,89}$ or in practice. ${ }^{43,47,49,81,109,110}$ Six used individual outcome measure, $43,47,49,89,109,110$ two of which were suitable to include in a meta-analysis. ${ }^{43,89}$. The pooled estimate was not significant $(\mathrm{OR}=1.01,1.00-1.02)$ (Fig. 3). Of the four other studies which examined individual measures, ${ }^{47,49,109,110}$ three found no association, ${ }^{47,49,110}$ while one reported physicians with $>15$ years in practice had higher odds of proteinuria testing. ${ }^{109}$ 


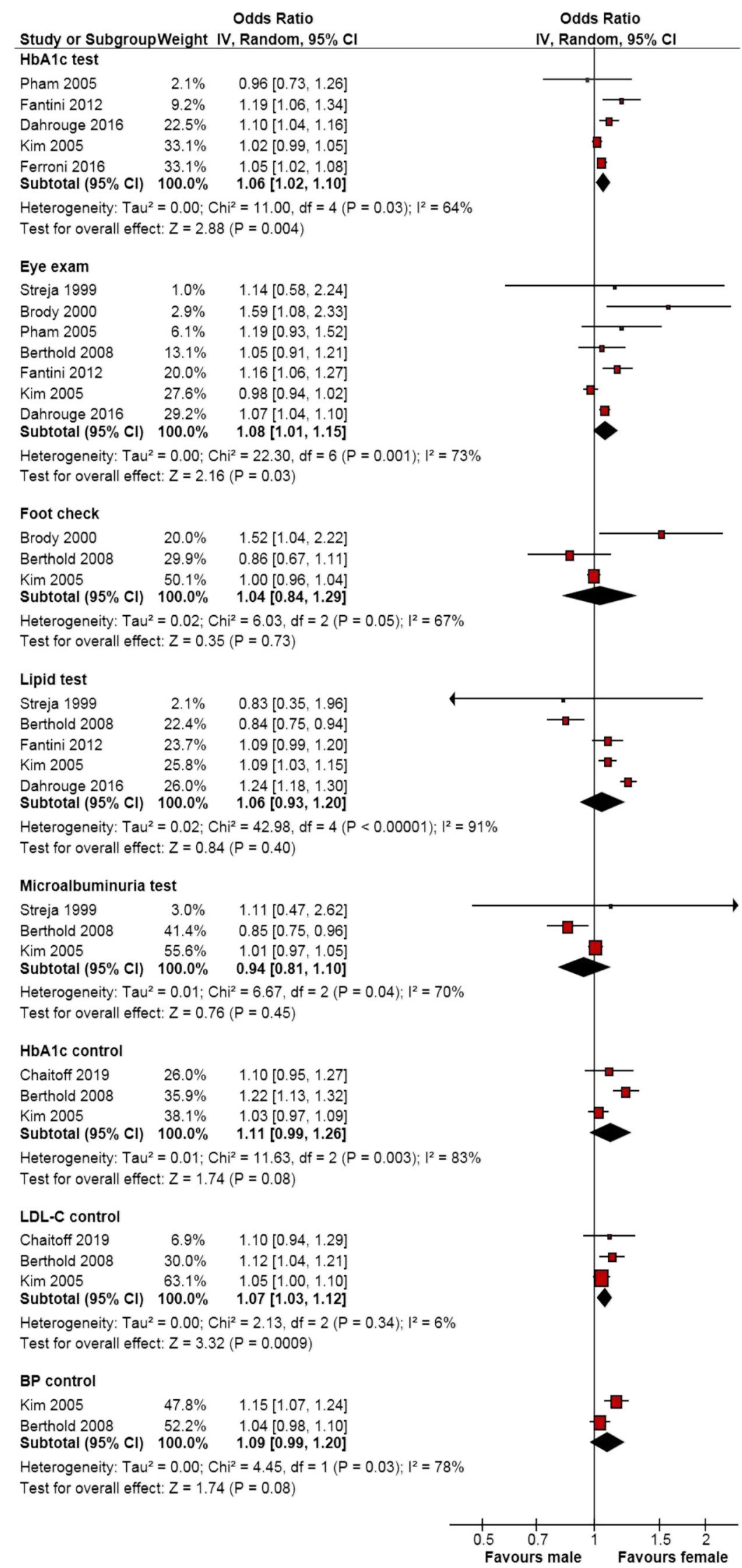

Fig. 2 Physician gender and individual measures of quality (pooled). Berthold et al. included patients with type 2 only; Ferroni et al. included non-insulin-treated patients only; Pham et al. analysed data from Medicare beneficiaries $\geq 65$ years. Berthold et al. used targets $\mathrm{HbA1c}<7.0 \%$ and LDL-C $<130 \mathrm{mg} / \mathrm{dl}$; Kim et al. used targets HbA1c $<8.5 \%$ and LDL-C $<130 \mathrm{mg} / \mathrm{dl}$. 
Odds Ratio

Study or Subgroup Weight IV, Random, $95 \% \mathrm{Cl}$

HbA1c control

$\begin{array}{llr}\text { McGinn } 2006 & 23.1 \% & 1.03[1.00,1.06] \\ \text { Spann } 2006 & 36.0 \% & 1.01[0.99 .1 .03] \\ \text { Subtotal }(95 \% \mathrm{CI}) & \mathbf{5 9 . 1 \%} & \mathbf{1 . 0 2 [ 1 . 0 0 , 1 . 0 4 ]}\end{array}$

Heterogeneity: $\mathrm{Tau}^{2}=0.00 ; \mathrm{Chi}^{2}=1.30, \mathrm{df}=1(\mathrm{P}=0.25) ; \mathbf{I}^{2}=23 \%$

Test for overall effect: $Z=1.88(P=0.06)$

Lipid control

$\begin{array}{lll}\text { McGinn } 2006 & 23.1 \% & 0.99[0.97,1.02] \\ \text { Spann } 2006 & 17.8 \% & 1.01[0.98,1.04] \\ \text { Subtotal }(95 \% \mathrm{Cl}) & \mathbf{4 0 . 9 \%} & \mathbf{1 . 0 0 [ 0 . 9 8 , 1 . 0 2 ]}\end{array}$

Heterogeneity: $\mathrm{Tau}^{2}=0.00 ; \mathrm{Chi}^{2}=0.68, \mathrm{df}=1(\mathrm{P}=0.41) ; \mathrm{I}^{2}=0 \%$

Test for overall effect: $Z=0.03(P=0.98)$

Total $(95 \% \mathrm{Cl}) \quad 100.0 \% \quad 1.01[1.00,1.02]$

Heterogeneity: $\mathrm{Tau}^{2}=0.00 ; \mathrm{Ch}^{2}=3.64, \mathrm{df}=3(\mathrm{P}=0.30) ; \mathrm{I}^{2}=18 \%$

Test for overall effect: $Z=1.49(P=0.14)$

Test for subgroup differences: $\mathrm{Chi}^{2}=1.57, \mathrm{df}=1(\mathrm{P}=0.21), \mathrm{I}^{2}=36.4 \%$
Odds Ratio

IV, Random, $95 \% \mathrm{Cl}$

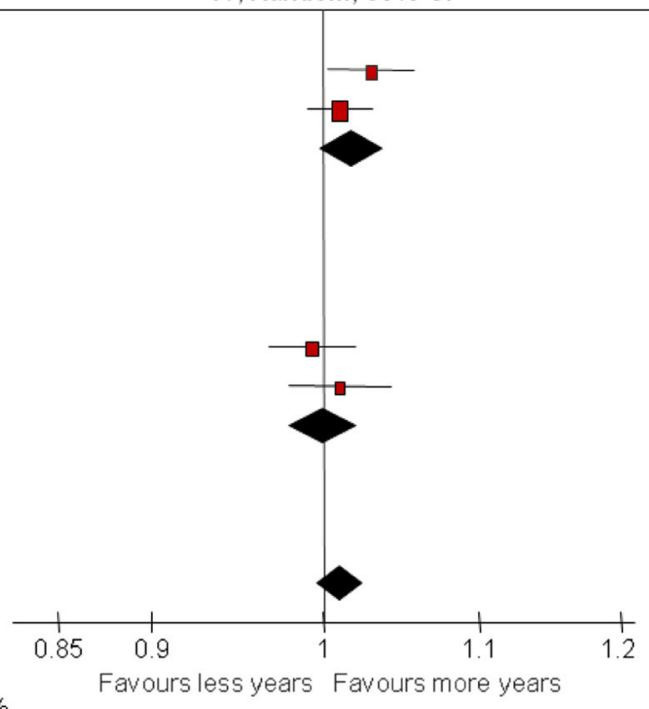

Fig. 3 Physician years of experience and individual measures of quality (pooled). Spann et al. used targets HbA1c $<7.0 \%$ and LDL-C $<100 \mathrm{mg} /$ dl; McGinn et al. used targets HbA1c $<9 \%$ and LDL-C $<130 \mathrm{mg} / \mathrm{dl}$.

Composite Measures. Two studies used a composite measure of quality. ${ }^{80,81}$ Only one had data available. ${ }^{80}$ Neither study reported experience was associated with quality. ${ }^{80,81}$

\section{Diabetes Volume}

Individual Measures. Eight studies examined the volume of patients with diabetes per physician. ${ }^{49}, 55,99,107,109,111-113$ One study examined clinical inertia. ${ }^{113}$ Seven used individual outcome measures $^{49,55,99,107,109,111,112}$, four of which were included in a meta-analysis. ${ }^{107,} 109,111,112$ The pooled estimate indicated higher volume was associated with higher quality $(\mathrm{OR}=1.24,1.05-1.47)$ (Fig. 4). Three other studies examined individual measures ${ }^{49}, 55,99$ one of which found higher volume was associated with higher quality. ${ }^{55}$

Composite Measures. Only one study used a composite measure $^{111}$ and found higher volume was associated with higher quality. ${ }^{11}$

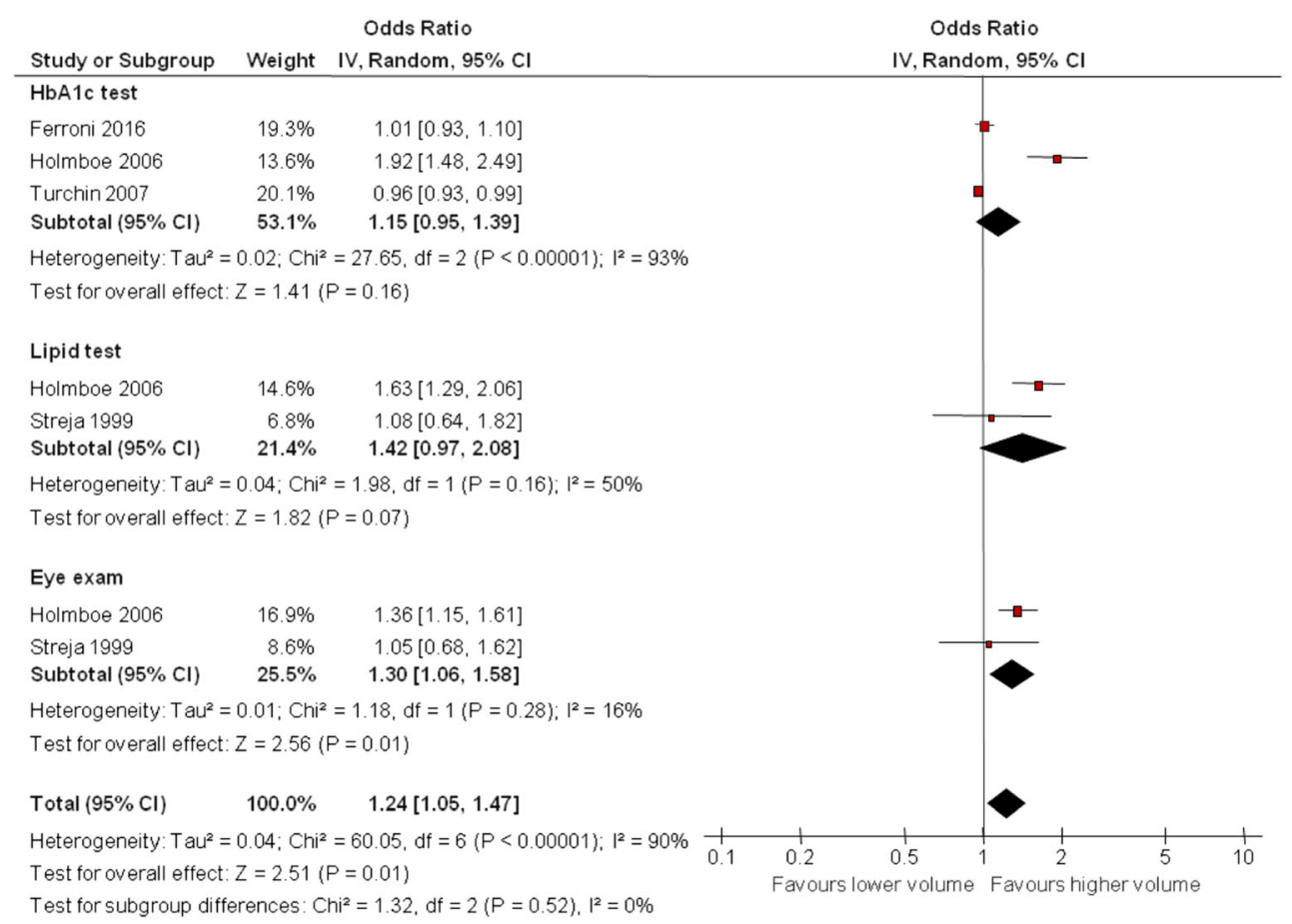

Fig. 4 Physician volume of patients with diabetes and individual measures of quality (pooled) Holmboe et al. volume group V (32-66 patients) vs. volume group I (1-4 patients); Ferroni et al. 56-70 patients vs. $\leq 55$ patients; Turchin et al. per 10 patients annually; Streja et al. $>20$ patients vs. $\leq \mathbf{2 0}$ patients. 


\section{Other Physician Factors}

Other common primary care physician factors ( $\geq 5$ studies) not included in a meta-analysis were age, 47, 51, 57, 69, 81, 89, 93, 99, 104, 107, 110,113 training, $42,66,72,81,88,93,103,105$ and panel size/workload. ${ }^{37}$, $43,49,55,57,68,69,71,81,97,99,103,104,114$ The relationship of panel size with quality was inconsistent. Seven of twelve studies examining physician age reported a significant association: older physician age was associated with lower quality. ${ }^{57,69,89,99,104,107,113}$ Four of seven studies examining training reported a significant positive association with quality. $42,81,88,93$

\section{PRACTICE FACTORS}

\section{Location}

Individual Measures. Ten studies examined practice location (rural vs. urban). ${ }^{40,47,56,57,73,81,83,102-104}$ Three examined individual measures. ${ }^{40,47,73}$ These were not included in a meta-analysis. One found no association with quality. ${ }^{47}$ Results were inconsistent among the other two studies. ${ }^{40,73}$

Composite Measures. Eight studies used a composite measure $50,56,57,81,83,102-104$, three of which included in a meta-analysis. ${ }^{83,} 102,104$ There was no association between location and quality $(\mathrm{OR}=1.02$, 0.87-1.19) (Fig. 5a). Of the five other composite studies, three found no association with quality, ${ }^{57,} 81$, 103 two reported mixed results by intervention $\mathrm{arm}^{56}$ and one favoured urban practices. ${ }^{50}$

\section{Type of Practice}

Individual Measures. Twelve studies compared group with solo/single-handed practices. $37,44,45,47,58,66-68,71,89,104,105$ Nine studies used individual outcome measures, $37,44,45,47,66$,

\section{(a) Location}

Odds Ratio

Odds Ratio

Study or Subgroup Weight IV, Random, $95 \% \mathrm{Cl}$

IV, Random, $95 \% \mathrm{CI}$

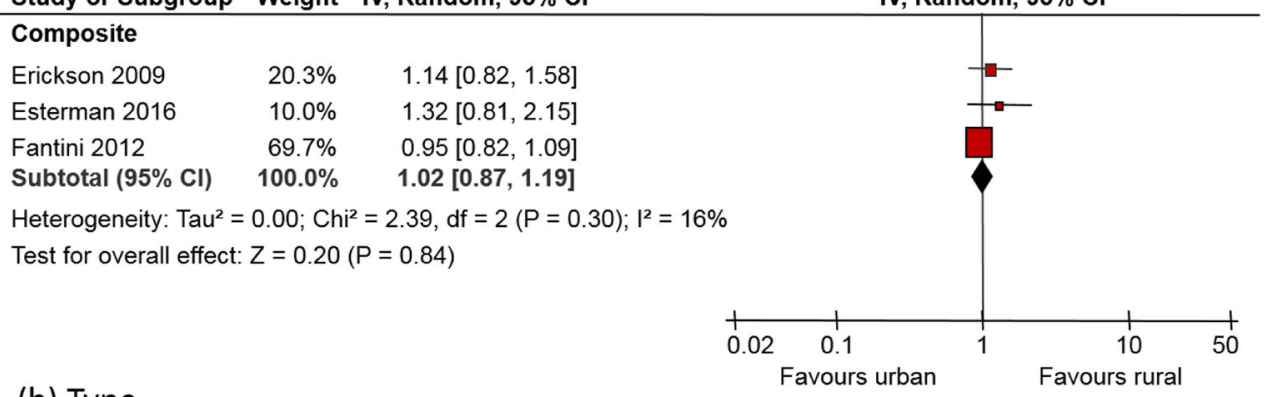

(b) Type

Odds Ratio

Odds Ratio

Study or Subgroup Weight IV, Random, $95 \% \mathrm{Cl}$ HbA1c test

$\begin{array}{lll}\text { McGinn } 2006 & 14.1 \% & 0.96[0.59,1.54] \\ \text { Pham } 2005 & 19.7 \% & 1.91[1.40,2.61]\end{array}$

Subtotal $(95 \% \mathrm{Cl}) \quad 33.8 \% \quad 1.39[0.70,2.72]$

Heterogeneity: Tau $^{2}=0.20 ; \mathrm{Chi}^{2}=5.69, \mathrm{df}=1(\mathrm{P}=0.02) ; \mathrm{I}^{2}=82 \%$

Test for overall effect: $Z=0.95(P=0.34)$

Eye exam

$\begin{array}{lll}\text { McGinn } 2006 & 14.0 \% & 0.79[0.49,1.28] \\ \text { Pham 2005 } & 19.9 \% & 1.23[0.91,1.68]\end{array}$

Subtotal $(95 \% \mathrm{Cl}) \quad 33.9 \% \quad 1.03[0.67,1.58]$

Heterogeneity: $\mathrm{Tau}^{2}=0.06 ; \mathrm{Chi}^{2}=2.35, \mathrm{df}=1(\mathrm{P}=0.13) ;\left.\right|^{2}=57 \%$

Test for overall effect: $Z=0.13(P=0.90)$

Composite

$\begin{array}{lrr}\text { Crosson } 2007 & 7.0 \% & 2.63[1.15,6.02] \\ \text { Fantini } 2012 & 25.3 \% & 1.18[1.01,1.38]\end{array}$

$\begin{array}{lrr}\text { Fantini } 2012 & 25.3 \% & 1.18[1.01,1.38] \\ \text { Subtotal }(95 \% \mathrm{Cl}) & \mathbf{3 2 . 3} \% & \mathbf{1 . 5 8}[0.74,3.38]\end{array}$

Heterogeneity: $\mathrm{Tau}^{2}=0.23 ; \mathrm{Chi}^{2}=3.48, \mathrm{df}=1(\mathrm{P}=0.06) ; \mathrm{I}^{2}=71 \%$

Test for overall effect: $Z=1.19(P=0.24)$

Total $(95 \% \mathrm{Cl}) \quad 100.0 \% \quad 1.27[0.99,1.64]$

Heterogeneity: $\mathrm{Tau}^{2}=0.06 ; \mathrm{Chi}^{2}=15.52, \mathrm{df}=5(\mathrm{P}=0.008) ; \mathrm{l}^{2}=68 \%$

Test for overall effect: $Z=1.85(P=0.06)$

Test for subgroup differences: $\mathrm{Chi}^{2}=1.18, \mathrm{df}=2(\mathrm{P}=0.55), \mathrm{I}^{2}=0 \%$

IV, Random, $95 \% \mathrm{Cl}$

Fig. 5 Practice location and type and quality of care (pooled). 
$67,89,104,105$ three of which were included in a meta-analysis. $^{89,104,105}$ There was an association between practice type and delivery of lipid test (favouring group practices) (Suppl.Figure 4). Of six other studies examining individual measures, $37,44,45,47,66,67$ four found no association, ${ }^{37,44,47,}$ ${ }^{67}$ one found group practices performed better on some measures $^{66}$ and one found patients attending group practices were more likely to be treated with lipid-lowering drugs. ${ }^{45}$

Composite Measures. Four studies used a composite outcome measure, ${ }^{58,68,71,104}$ and two were included in a metaanalysis. There was no association between practice type and a composite quality measure $(\mathrm{OR}=1.58,0.74-3.38)$ (Fig. 5b). Of two other composite studies, one reported an association favouring group practices. ${ }^{71}$

There was no association between type and quality overall (any measure, individual or composite) and high statistical heterogeneity $\left(I^{2}=68 \%\right)(\mathrm{OR}=1.27,0.99-1.64)$ (Fig. 5b).

\section{Electronic Health Records}

Individual Measures. Sixteen studies examined the use of EHRs. $^{41,43,56-58,60,63, ~ 66, ~ 84, ~ 85, ~ 90, ~ 94, ~ 102, ~ 105, ~ 115, ~} 116$
Five studies examined individual measures, 43, 63, 66, 105, 115 two of which were included in a meta-analysis. ${ }^{43}, 66$ Having an EHR was only significantly associated with one measure, HbA1c control (OR=1.54, 1.11-2.14) (Suppl.Figure 5). Of three other studies examining individual measures ${ }^{63,105,115}$ all found the presence/use of an EHR was associated with better performance on some measures. ${ }^{63,105,115}$

Composite Measures. Eleven studies used a composite quality measure. $^{41,} 56-58,60,84,85,90,94,102,116$ Two studies using the same exposure (EHR vs. none) were included in a meta-analysis. ${ }^{41,57,58,84}$ A practice EHR was associated with higher quality $(\mathrm{OR}=2.23,1.60$ 3.09) (Fig. 6). Of nine other studies using composite measures, ${ }^{56}, 57,60,84,85,90,94,102,116$ four did not report a significant association ${ }^{56}, 85,90,102$ while five found the presence/use of a practice EHR was associated with better performance. ${ }^{57,60,84,94,116}$

Overall, practices with EHRs were more likely to achieve higher quality (any measure, individual or composite) $(\mathrm{OR}=$ 1.43, 1.11-1.84) (Fig. 6).

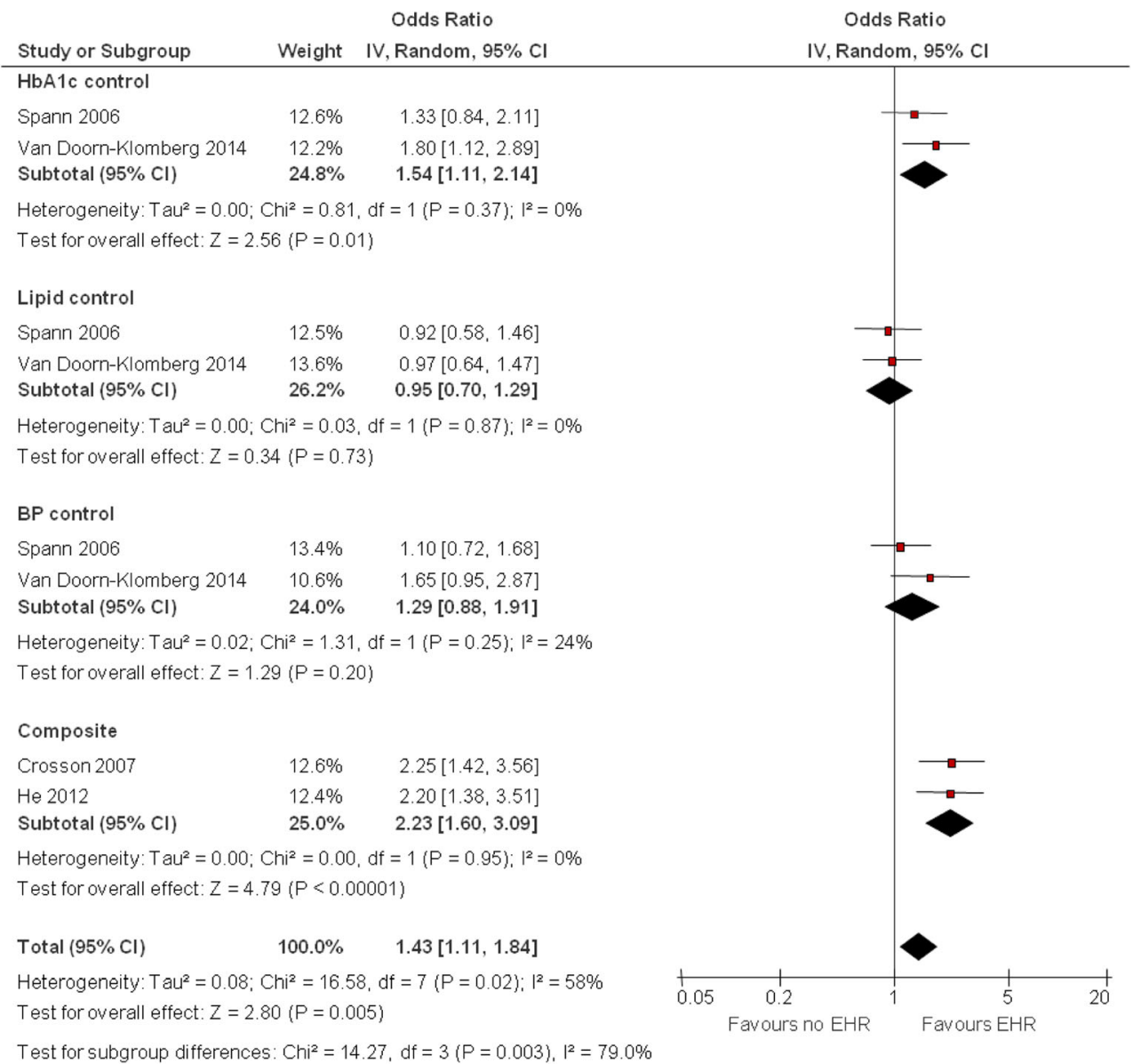

Fig. 6 Electronic Health Record (EHR) at practice and the association with quality (pooled). He et al. estimates relate to older men only, estimates for older women were not significant $(\mathrm{OR}=1.1,0.63-1.91)$, with inclusion of this data the pooled estimate is still significant. Van Doorn Klomberg et al. compared practice performance in highest vs. lowest quartile for HbA1c, BP and cholesterol control; Spann et al. used targets for good control of HbA1c $(\leq 7 \%)$, BP $(\leq 130 / 85 \mathrm{mmHg})$ and $\mathrm{LDL}-\mathrm{C}(<100 \mathrm{mmol} / \mathrm{mol})$. 


\section{Other Practice Factors}

Other practice factors identified ( $\geq 5$ studies) were practice deprivation, ${ }^{38,54,64,67,68,70,71,86,103,117,118}$ diabetes prevalence ${ }^{38}$, $47,64,67,68,71,86,87,103,117$ or volume ${ }^{45,51,69,73,84,116,119}$

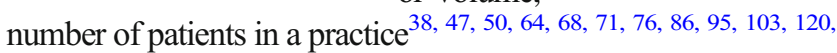
${ }^{121}$, number of GPs, ${ }^{37,54,56,61,64,69,70,80,95,102,103}$ or nurses, ${ }^{64}$, $66,68,71,95,102,103$ nurse or physician assistant involvement, ${ }^{39,} 43$, $45,47,52,59,65,73,121-123$ and use of a register/recall system. ${ }^{43,46 \text {, }}$ $64,66,72,78,103$ The relationship of these factors with quality was inconsistent. One exception was practice socio-economic deprivation; all studies which reported a significant association (8/11) found higher deprivation was associated with lower quality. ${ }^{38,64 \text {, }}$ $67,71,86,103,117,118$

\section{DISCUSSION}

Based on studies combined in a meta-analysis, this review identified female gender, higher physician volume of patients with diabetes and a practice EHR favoured higher quality of care in primary care. Findings were not significant for physician experience, practice location or type. Among studies not included in a meta-analysis, some evidence suggested that increasing physician age and higher practice deprivation were associated with lower quality. As such, most factors were not modifiable. The range of individual quality measures and the construction of composite measures varied considerably.

The association between female physicians and higher quality of care is consistent with existing research examining preventative care for women ${ }^{124,} 125$, management of chronic health failure ${ }^{126}$ and inpatient care. ${ }^{127}$ Provider attitudes and beliefs about diabetes ${ }^{128}$, the quality of patient-provider communication and interpersonal skills ${ }^{18,128}$, can support or hinder management. Previous work has posited that different communication styles between male and female physicians ${ }^{129}$ and/or greater focus by female physicians on preventive care ${ }^{130,131}$ may be some reasons for differences in the quality of care.

Just over half of the included studies examining physician age reported a significant association. The finding, that older age is associated with poorer quality, fits with some studies of age/ experience among hospital and primary care-based phyisicans $^{132-134}$, but not all. ${ }^{135,136}$ Ultimately the evidence is mixed, with more work needed to understand the relationship and reach a definitive conclusion. Older GPs may be less inclined to adopt and implement new practices and standards of care. ${ }^{137}$ Also, they may only appear to have a lower quality of care; as senior physicians, they may have an older and more complex patient cohort. However, most studies controlled for patient comorbidities or patient complexity. ${ }^{57,69,99,104,107}$ Notably few adjusted for practice factors ${ }^{57,69,89,104}$; the mixed findings may reflect unaccounted for practice factors, e.g. academic-affiliation or private/public status. If GPs deliver care differently according to their age or practice position understanding why could drive strategies to better support care delivery, e.g. continuing education or addressing their caseload.
In terms of caseload, the diabetes volume-quality relationship is less clear. The relationship between practice-level diabetes prevalence or volume and quality was inconsistent. However, in a meta-analysis we found diabetes volume at the physician level was positively associated with quality, fitting with work in the acute setting. ${ }^{138,139}$ We may expect practices with high diabetes prevalence to be more proactive in improving management. However, higher utilization by people with diabetes ${ }^{140}$ may place greater demand on practice staff and resources, with a negative effect on quality. The association between prevalence and poorer quality reported by some of the studies could also reflect the higher prevalence in more deprived areas ${ }^{141,}{ }^{142}$, given deprivation was negatively associated with quality. ${ }^{38,64,67,86,117,118}$ The positive relationship between physician-level diabetes volume and quality of care could reflect greater expertise gained through more exposure, ${ }^{139}$ and may suggest the benefits of having a GP or nurse dedicated to diabetes care delivery; care models involving GPs with specialist interest have demonstrated a positive impact on outpatient attendances ${ }^{143,144}$ and HbAlc control. ${ }^{145}$

Our findings on practice location do not reflect challenges faced by rural practices, particularly in the US; i.e., limited access to specialists, funding and educational opportunities. ${ }^{146}$ However, most studies could not be included in a meta-anal-

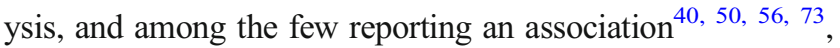
findings were mixed. In the USA, private practices outside of federally qualified health centres or academic centres face similar resourcing challenges ${ }^{147,}{ }^{148}$, further suggesting the importance of these unaccounted for practice factors.

Our finding that practices with EHRs performed better supports existing qualitative work suggesting the quality of information technology ${ }^{18}$ and lack of EHRs ${ }^{149}$ is a barrier to diabetes management. The magnitude of the overall effect estimate across quality measures $(\mathrm{OR}=1.43,1.11-1.84)$ was greater than that observed for physician gender $(\mathrm{OR}=1.06$, $1.03-1.10)$ or diabetes volume $(\mathrm{OR}=1.24,1.05-1.47)$. The effect (relative risk of receipt of care processes) achieved in trials of diabetes QI interventions has been found to range from $1.22(1.13-1.32)$ for eye screening to $1.28(1.13-1.44)$ for performance of a renal function check. ${ }^{13}$ With ongoing calls to develop electronic healthcare (e-health) in primary care $^{150}$, as a modifiable factor, EHR adoption should be facilitated as part of QI interventions.

Given most factors were not modifiable it is important (1) to be cognisant of these factors and how they could influence implementation of service changes and (2) to consider tailoring to accommodate these factors when introducing interventions or service changes into routine practice. Changes introduced widely (e.g. within a national health service like the UK NHS) or in specific sectors or organisations (e.g. Department of Veterans Affairs or Kaiser Permanente in the USA) could involve practices delivering care in different contexts, i.e. without an EHR, a longer established practice with older GPs, higher diabetes volume or based in a deprived area. Practices may implement initiatives differently, adapting to 
the 'normal conditions' 151 of their practice, contextual features which may contribute to the 'evidence to practice' gap and yet not necessarily accounted for during evaluative studies.

For example, information technologies (EHRs) need to be well designed to enhance existing practice and not place additional demands on staff. ${ }^{152,}{ }^{153}$ Their implementation should be considered in light of other non-modifiable factors, e.g. caseload, diabetes volume (and clinician skills/experience as a result). Staff with appropriate skills are crucial to underpin the $\mathrm{CCM}^{152,153}$ However, education and caseload are difficult to address within the constrained primary care setting. Solutions proposed involve task delegation to non-physician staff ${ }^{17}$ (e.g. panel management assistants in Kaiser Permanente ${ }^{154}$ ), nurse substitution ${ }^{155}$ or co-located or outreach specialists. ${ }^{156}$, ${ }^{157}$ For example, specialist nurses conducting clinics in practices, can provide inhouse education and support. ${ }^{158-161}$ While plausible, these approaches require not only sufficient resourcing of outreach specialists ${ }^{159}$, particularly in rural primary care ${ }^{162}$ but protected physician/practice time (e.g. to direct panel management, liaise with specialists to identify education and organizational needs and tailor support accordingly ${ }^{160}, 163$ ). In the US context, these approaches may be more feasible in larger, hospital-affiliated practices.

While this review did not use Wagner's Chronic Care Model (CCM) as a framework a priori, some factors identified are relevant to the model. ${ }^{164}$ For example, physician-patient communication is central to patient self-management support, a key element of the CCM. ${ }^{165}$ Given our findings on physician gender, further exploration of communication styles between male and female physicians specifically as they relate to selfmanagement is warranted. In line with the CCM framework $^{164}$, we found information systems (EHRs) were associated with higher quality of care. Together with supporting the core components of structured care delivery (i.e. register/recall) EHRs facilitate additional capabilities like clinician decision support ${ }^{166}$, another CCM element posited to drive highquality care.

In line with an existing review, we identified variability in the number and type of quality indicators used across studies. ${ }^{30}$ This suggests the need for better selection criteria when choosing indicators and agreement on a standardised composite quality of diabetes care measure.

\section{STRENGTHS AND LIMITATIONS}

Unlike reviews focusing on one specific practice factor $^{167}$, we used broad search terms together with a range of a priori factors to identify all possible studies which examined a given factor. It is possible our search strategy may have missed other specific factors not identified a priori. However, we are confident we have identified all literature for the a priori factors $(n=19)$ and for the main additional factors ( $\geq 5$ studies). Furthermore, reviewing the reference lists indicated that most relevant studies had been identified. As our review includes factors which may not be the study focus (e.g. model covariate but with available effect estimates) data were less well-reported and sometimes not available from study authors. For example, data were often not reported for factors found to have no significant association with quality.

Included studies were, for the most part, cross-sectional, and the causal relationship between physician and practice factors is tentative. Owing to variation in exposures and outcomes used, together with the lack of reported data, the meta-analyses included only a small number of studies and results should be interpreted with caution. To aid the reader we have also summarised the findings from the studies which could not be included in a meta-analysis. Some analyses indicated considerable statistical heterogeneity $\left(I^{2}>60 \%\right)$. As few studies could be included in the meta-analyses this precludes an investigation of sources of heterogeneity; however, we suggest this was largely due to variation in composite outcome measures. We provide details of these measures for the reader to make their own judgement.

\section{CONCLUSION}

As stated by the Institute of Medicine in their seminal report, quality is a property of institutions, not individuals. ${ }^{168,169}$ Our findings may inform targeted support of practice-level improvements and guide strategies to better implement structured diabetes management. Further research is needed: (1) to understand the way in which specific physician profile (gender, age and experience) and diabetes volume influences quality and (2) to examine the impact of practice rurality and status (academic-affiliation, public/private) which could not be adequately examined. Lastly, agreement on standard composite quality measures is crucial to increase comparability across studies and establish a clear picture of the quality of diabetes management in primary care.

Corresponding Author: F. Riordan, PhD; School of Public HealthUniversity College Cork, Western Gateway Building, Western Rd, Cork, Ireland (e-mail: fiona.riordan@ucc.ie).

\begin{abstract}
Authors' Contribution All authors have made substantial contributions to conception and design, acquisition of data or analysis and interpretation of data. They have all participated in drafting the paper or revising it critically for important intellectual content. All authors have read and approved the final version of the manuscript.
\end{abstract}

Funding This study was funded by the Health Research Board in Ireland. The funder played no role in the design, conduct, or reporting.

\section{Compliance with Ethical Standards:}

Conflict of Interest: The authors declare that they do not have a conflict of interest. 


\section{REFERENCES}

1. Griffin S, Kinmonth AL. Diabetes care: the effectiveness of systems for routine surveillance for people with diabetes. Cochrane Database Syst Rev. 2000(2):Cd000541.

2. Kahn R, Anderson JE. Improving Diabetes Care: The Model for Health Care Reform. Diabetes Care 2009;32(6):1115-8.

3. American Diabetes Association. 4. Foundations of Care: Education, Nutrition, Physical Activity, Smoking Cessation, Psychosocial Care, and Immunization. Diabetes Care. 2015;38(Supplement 1):S20-S30.

4. Irish College of General Practitioners (ICGP). A Practical Guide to Integrated Type 2 Diabetes Care Dublin: Irish College of General Practitioners 2016.

5. National Institute for Health and Care Excellence (NICE). Type 2 diabetes in adults: management. London: National Institute for Health and Care Excellence; 2015.

6. Stone MA, Charpentier G, Doggen K, et al. Quality of care of people with type 2 diabetes in eight European countries: findings from the Guideline Adherence to Enhance Care (GUIDANCE) study. Diabetes Care. 2013;36(9):2628-38.

7. Khunti K, Ceriello A, Cos X, et al. Achievement of guideline targets for blood pressure, lipid, and glycaemic control in type 2 diabetes: A metaanalysis. Diabetes Res Clin Pract.137:137-48.

8. Felton AM, Hall MS. Diabetes - from St Vincent to Glasgow. Have we progressed in 20 years? British Journal of Diabetes and Vascular Disease. 2009;9(4):142-4.

9. Ali MK, Bullard KM, Gregg EW. Achievement of goals in U.S. Diabetes Care, 1999-2010. N Engl J Med. 2013;369(3):287-8.

10. Stark Casagrande S, Fradkin JE, Saydah SH, et al. The Prevalence of Meeting A1C, Blood Pressure, and LDL Goals Among People With Diabetes, 1988-2010. Diabetes Care 2013;36(8):2271-9.

11. Mahase E. Progress in diabetes care has not improved outcomes in US, study finds. BMJ. 2019;366:15166.

12. Bongaerts BWC, Mussig K, Wens J, et al. Effectiveness of chronic care models for the management of type 2 diabetes mellitus in Europe: a systematic review and meta-analysis. BMJ Open. 2017;7:e013076.

13. Tricco AC, Ivers NM, Grimshaw JM, et al. Effectiveness of quality improvement strategies on the management of diabetes: a systematic review and meta-analysis. Lancet. 2012;379(9833):2252-61.

14. Woolf $\mathrm{SH}$. The meaning of translational research and why it matters. JAMA. 2008;299(2):211-3.

15. Grol R, Grimshaw J. From best evidence to best practice: effective implementation of change in patients' care. The Lancet. 2003;362(9391):1225-30.

16. Bodenheimer T, Chen E, Bennett HD. Confronting The Growing Burden Of Chronic Disease: Can The U.S. Health Care Workforce Do The Job? Health Aff (Millwood). 2009;28(1):64-74.

17. Bodenheimer T, Pham HH. Primary care: current problems and proposed solutions. Health Aff (Millwood). 2010;29(5):799-805.

18. Rushforth B, McCrorie C, Glidewell L, et al. Barriers to effective management of type 2 diabetes in primary care: qualitative systematic review. Br J Gen Pract. 2016;66(643):e114-27.

19. Barry M BK, Brick A, Morgenroth E, Normand C, O'Reilly J, Thomas S, Wiley M. Projecting the Impact of Demographic Change on the Demand for and Delivery of Health Care in Ireland. Dublin: Economic and Social Research Institute; 2009.

20. McDaid D WM, Maresso M, Mossialos E. Ireland: Health system review. Health Systems in Transition: European Observatory on Health Systems and Policies; 2009

21. National Doctor Training and Planning HD. Medical Workforce Planning. Future Demand for General Practitioners. 2015-2025. Dublin: Health Service Executive,; 2015.

22. Majeed A. Shortage of general practitioners in the NHS. BMJ. 2017;358:j3191.

23. Papp M, Korosi L, Sandor J, et al. Workforce crisis in primary healthcare worldwide: Hungarian example in a longitudinal follow-up study. BMJ Open. 2019;9(7):e024957.

24. Berwick DM, Hackbarth AD. Eliminating Waste in US Health Care. JAMA. 2012;307(14):1513-6.

25. Petterson SM, Liaw WR, Tran C, et al. Estimating the residency expansion required to avoid projected primary care physician shortages by 2035 . Ann Fam Med. 2015;13(2):107-14

26. Wensing M, Oxman A, Baker R, et al. Tailored implementation for chronic diseases (TICD): A project protocol. Implementation Science. 2011;6(1):103.
27. Moher D, Liberati A, Tetzlaff J, et al. Preferred Reporting Items for Systematic Reviews and Meta-Analyses: The PRISMA Statement. PLoS Med. 2009;6(7):e1000097.

28. Riordan F., Nomsa Mtshede M., O’Donovan C., et al. Assessing the effect of patient, physician and practice characteristics on the quality of diabetes management in primary care: a systematic review of the literature. PROSPERO CRD42017072274. 2017.

29. Effective Practice and Organisation of Care (EPOC). EPOC Taxonomy 2015 [Available from: https://epoc.cochrane.org/epoc-taxonomy. Accessed February 2019.

30. Braspenning J, Faber MJ, Wensing M, et al. Performance measurements in diabetes care: the complex task of selecting quality indicators. Int J Qual Health Care. 2013;25(6):704-9.

31. O'Connor PJ, Bodkin NL, Fradkin J, et al. Diabetes Performance Measures: Current Status and Future Directions. Diabetes Care. 2011;34(7):1651.

32. Rodriguez-Gutierrez R, McCoy RG. Measuring What Matters in Diabetes. Reevaluating the Use of Hemoglobin Alc as a Surrogate Marker in Diabetes. 2019

33. Lipska KJ, Krumholz HM. Is hemoglobin alc the right outcome for studies of diabetes? JAMA. 2017;317(10):1017-8.

34. Joanna Briggs Institute (JBI). Critical Appraisal Tools. Available from: http://joannabriggs.org/research/critical-appraisal-tools.html

35. Altman DG, Bland JM. How to obtain the confidence interval from a P value. BMJ. 2011;343.

36. Altman DG, Bland JM. How to obtain the P value from a confidence interval. BMJ. 2011;343.

37. Juul L, Sandbaek A, Foldspang A, et al. Adherence to guidelines in people with screen-detected type 2 diabetes, ADDITION, Denmark Exemplified by treatment initiation with an ACE inhibitor or an angiotensin-II receptor antagonist. Scand J Prim Health Care. 2009;27(4):223-31.

38. Millett C, Car J, Eldred D, et al. Diabetes prevalence, process of care and outcomes in relation to practice size, caseload and deprivation: national cross-sectional study in primary care. Journal of the Royal Society of Medicine. 2007;100(6):275-83.

39. Lutfiyya MN, Tomai L, Frogner B, et al. Does primary care diabetes management provided to Medicare patients differ between primary care physicians and nurse practitioners? Journal of advanced nursing. 2017;73(1):240-52.

40. Weiner JP, Parente ST, Garnick DW, et al. Variation in office-based quality. A claims-based profile of care provided to Medicare patients with diabetes. JAMA. 1995;273(19):1503-8.

41. He XZ. Diabetes care for older patients in America. Int $\mathrm{J}$ Clin Pract. 2012;66(3):299-304.

42. Holmboe ES, Wang Y, Meehan TP, et al. Association between maintenance of certification examination scores and quality of care for medicare beneficiaries. Arch Intern Med. 2008; 168(13): 1396-403.

43. Spann SJ, Nutting PA, Galliher JM, et al. Management of type 2 diabetes in the primary care setting: a practice-based research network study. Ann Fam Med. 2006;4(1):23-31.

44. Bower P, Campbell S, Bojke C, et al. Team structure, team climate and the quality of care in primary care: an observational study. Quality \& Safety in Health Care. 2003;12(4):273-9.

45. Cho YY, Sidorenkov G, Denig P. Role of Patient and Practice Characteristics in Variance of Treatment Quality in Type 2 Diabetes between General Practices. PLoS One. 2016;11(11):e0166012-e.

46. Spigt M, Stefens C, Passage D, et al. The relationship between primary health care organization and quality of diabetes care. Eur J Gen Pract. 2009; 15(4):212-8.

47. van Bruggen $\mathrm{R}$, Gorter $\mathrm{K}$, Stolk $\mathrm{R}$, et al. Clinical inertia in general practice: widespread and related to the outcome of diabetes care. Fam Pract. 2009;26(6):428-36.

48. Berthold HK, Gouni-Berthold I, Bestehorn KP, et al. Physician gender is associated with the quality of type 2 diabetes care. J Intern Med. 2008;264(4):340-50.

49. Bralić Lang V, Bergman Marković B, Kranjčević K. Family physician clinical inertia in glycemic control among patients with type 2 diabetes. Medical Science Monitor: International Medical Journal Of Experimental And Clinical Research. 2015;21:403-11.

50. Matthews V, Schierhout G, McBroom J, et al. Duration of participation in continuous quality improvement: a key factor explaining improved delivery of Type 2 diabetes services. BMC Health Serv Res. 2014;14:578-. 
51. Balkau B, Bouée S, Avignon A, et al. Type 2 diabetes treatment intensification in general practice in France in 2008-2009: the DIAttitude Study. Diabetes Metab. 2012;38 Suppl 3:S29-S35.

52. Juul L, Maindal HT, Frydenberg M, et al. Quality of type 2 diabetes management in general practice is associated with involvement of general practice nurses. Prim Care Diabetes. 2012;6(3):221-8.

53. Tran AT, Bakke Å, Berg TJ, et al. Are general practitioners character istics associated with the quality of type 2 diabetes care in general practice? Results from the Norwegian ROSA4 study from 2014. Scandinavian Journal of Primary Health Care. 2018;36(2): 170-9.

54. Willis TA, West R, Rushforth B, et al. Variations in achievement of evidence-based, high-impact quality indicators in general practice: An observational study. PLoS ONE. 2017;12(7).

55. Cheung A, Stukel TA, Alter DA, et al. Primary Care Physician Volume and Quality of Diabetes Care: A Population-Based Cohort Study. Ann Intern Med. 2017;166(4):240-7.

56. Dickinson LM, Dickinson WP, Nutting PA, et al. Practice Context Affects Efforts to Improve Diabetes Care for Primary Care Patients: A Pragmatic Cluster Randomized Trial. J Gen Intern Med. 2015;30(4):476-82.

57. Kern LM, Barron Y, Dhopeshwarkar RV, et al. Electronic Health Records and Ambulatory Quality of Care. J Gen Intern Med. 2013;28(4):496503.

58. Crosson JC, Ohman-Strickland PA, Hahn KA, et al. Electronic medical records and diabetes quality of care: results from a sample of family medicine practices. Ann Fam Med. 2007;5(3):209-15.

59. Ohman-Strickland PA, Orzano AJ, Hudson SV, et al. Quality of diabetes care in family medicine practices: influence of nurse-practitioners and physician's assistants. Ann Fam Med. 2008;6(1):14-22.

60. Orzano AJ, Strickland PO, Tallia AF, et al. Improving outcomes for high risk diabetics using information systems. Journal Of The American Board Of Family Medicine: JABFM. 2007;20(3):245-51.

61. Wang Y, O'Donnell CA, Mackay DF, et al. Practice size and quality attainment under the new GMS contract: a cross-sectional analysis. B J Gen Pract. 2006;56(532):830-5.

62. Campbell SM, Hann M, Hacker J, et al. Identifying predictors of high quality care in English general practice: observational study. Br Med J. 2001;323(7316):784-7.

63. Friedberg MW, Coltin KL, Safran DG, et al. Associations between structural capabilities of primary care practices and performance on selected quality measures. Ann Intern Med. 2009;151(7):456-63.

64. Khunti K, Ganguli S, Baker R, et al. Features of primary care associated with variations in process and outcome of care of people with diabetes. Br J Gen Pract. 2001;51(466):356-60.

65. Stearn R, Sullivan FM. Should practice nurses be involved in diabetic care? British Journal Of Nursing (Mark Allen Publishing). 1993;2(19):952-6.

66. van Doorn-Klomberg AL, Braspenning JCC, Wolters RJ, et al. Organizational determinants of high-quality routine diabetes care. Scand J Prim Health Care. 2014;32(3): 124-31.

67. Gulliford MC, Ashworth M, Robotham D, et al. Achievement of metabolic targets for diabetes by English primary care practices under a new system of incentives. Diabet Med. 2007;24(5):505-11.

68. Griffiths P, Maben J, Murrells T. Organisational quality, nurse staffing and the quality of chronic disease management in primary care: Observational study using routinely collected data. Int J Nurs Stud. 2011;48(10):1199-210.

69. Visca M, Donatini A, Gini R, et al. Group versus single handed primary care: A performance evaluation of the care delivered to chronic patients by Italian GPs. Health Policy. 2013;113(1-2):188-98.

70. Campbell SM, Hann M, Hacker J, et al. Identifying predictors of high quality care in English general practice: observational study. BMJ. 2001:323(7316):784-7.

71. Griffiths P, Murrells T, Maben J, et al. Nurse staffing and quality of care in UK general practice: cross-sectional study using routinely collected data. Br J Gen Pract. 2010;60(570):36-48

72. Dunn N, Pickering R. Does good practice organization improve the outcome of care for diabetic patients? Br J Gen Pract. 1998;48(430): 1237-40.

73. Ellerbeck EF, Engelman KK, Williams NJ, et al. Variations in diabetes care and the influence of office systems. Am J Med Qual. 2004;19(1):12-

74. Kamien M, Ward AM, Mansfield F, et al. Management of type 2 diabetes in Western Australian metropolitan general practice. Diabetes Res Clin Pract. 1994;26(3): 197-208.
75. McLean G, Guthrie B, Sutton M. Differences in the quality of primary medical care services by remoteness from urban settlements. Quality \& Safety in Health Care. 2007;16(6):446-9.

76. Tahrani AA, McCarthy M, Godson J, et al. Impact of practice size on delivery of diabetes care before and after the Quality and Outcomes Framework implementation. Br J Gen Pract. 2008;58(553):576-9.

77. Wang JJ, Cha J, Sebek KM, et al. Factors Related to Clinical Quality Improvement for Small Practices Using an EHR. Health Serv Res. 2014;49(6):1729-46.

78. Harris MF, Priddin D, Ruscoe W, et al. Quality of care provided by general practitioners using or not using Division-based diabetes registers. Med J Aust. 2002;177(5):250-2.

79. Parkerton $\mathrm{PH}$, Wagner EH, Smith DG, et al. Effect of part-time practice on patient outcomes. J Gen Intern Med. 2003;18(9):717-24.

80. Parkerton PH, Smith DG, Straley HL. Primary care practice coordination versus physician continuity. Fam Med. 2004;36(1):15-21

81. Vinker S, Lustman A, Elhayany A. Measurement of quality improvemen in family practice over two-year period using electronic database quality indicators: retrospective cohort study from Israel. Croat Med J. 2009;50(4):387-93.

82. Bredfeldt CE, Compton-Phillips AL, Snyder MH, et al. Effects of between visit physician-patient communication on Diabetes Recognition Program scores. Int J Qual Health Care. 2011;23(6):664-73.

83. Erickson RA, Targonski PV, Cox SB, et al. Does the 'office nurse' level of training matter in the family medicine office? J Am Board Fam Med. 2012;25(6):854-61.

84. McCullough JS, Christianson J, Leerapan B. Do electronic medical records improve diabetes quality in physician practices? The American Journal Of Managed Care. 2013;19(2):144-9.

85. Poon EG, Wright A, Simon SR, et al. Relationship between use of electronic health record features and health care quality: Results of a statewide survey. Med Care. 2010;48(3):203-9.

86. Suleman J, Anwar MS, Weston C, et al. Use of outcomes in monitoring healthcare - how many outcome measures are needed in monitoring diabetes in primary care? J R Soc Med. 2011;104(10):413-20.

87. Ricci-Cabello I, Stevens S, Kontopantelis E, et al. Impact of the Prevalence of Concordant and Discordant Conditions on the Quality of Diabetes Care in Family Practices in England. Ann Fam Med. 2015; 13(6):514-22.

88. Shuval K, Linn S, Brezis M, et al. Association between primary care physicians' evidence-based medicine knowledge and quality of care. Int J Qual Health Care. 2010;22(1):16-23.

89. McGinn J, Davis C. Geographic variation, physician characteristics, and diabetes care disparities in a metropolitan area, 2003-2004. Diabetes Res Clin Pract. 2006;72(2):162-9.

90. Keating NL, Landrum MB, Landon BE, et al. The influence of physicians' practice management strategies and financial arrangements on quality of care among patients with diabetes. Med Care. 2004;42(9):829-39.

91. Brody ER, Kohler SA, Rask KJ. Physician and patient characteristics associated with adherence to preventive care guidelines. J Clin Outcomes Manag. 2000;7(3):25-32.

92. Tabenkin H, Eaton CB, Roberts MB, et al. Differences in cardiovascular disease risk factor management in primary care by sex of physician and patient. Ann Fam Med. 2010;8(1):25-32.

93. Turchin A, Shubina M, Chodos AH, et al. Effect of board certification on antihypertensive treatment intensification in patients with diabetes mellitus. Circulation. 2008;117(5):623-8.

94. Cebul RD, Love TE, Jain AK, et al. Electronic Health Records and Quality of Diabetes Care. N Engl J Med. 2011;365(9):825-33.

95. Gulliford MC, Mahabir D, Ukoumunne OC. Evaluating variations in medical practice between government primary care health centres. J Clin Epidemiol. 2001;54(5):511-7.

96. Cho YY, Sidorenkov G, Denig P. Role of Patient and Practice Characteristics in Variance of Treatment Quality in Type 2 Diabetes between General Practices. PLoS One. 2016;11(11):e0166012.

97. Angstman KB, Horn JL, Bernard ME, et al. Family Medicine Panel Size with Care Teams: Impact on Quality. Journal Of The American Board Of Family Medicine: JABFM. 2016;29(4):444-51.

98. Berthold HK, Bestehorn KP, Jannowitz C, et al. Disease management programs in type 2 diabetes: quality of care. Am $\mathrm{J}$ Manag Care. 2011;17(6):393-403.

99. LeBlanc ES, Rosales AG, Kachroo S, et al. Do patient or provider characteristics impact management of diabetes? The American Journal Of Managed Care. 2015;21(9):597-606. 
100. Harris MI. Testing for blood glucose by office-based physicians in the U.S.. Diabetes Care. 1990;13(4):419-26.

101. Linder JA, Schnipper JL, Middleton B, et al. Method of electronic health record documentation and quality of primary care. J Am Med Inform Assoc. 2012;19(6):1019-24.

102. Esterman AJ, Fountaine T, McDermott R. Are general practice characteristics predictors of good glycaemic control in patients with diabetes? A cross-sectional study. Med J Aust. 2016;204(1):23.

103. Alberti H, Boudriga N, Nabli M. 'Damn Sokkor': factors associated with the quality of care of patients with diabetes: a study in primary care in Tunisia. Diabetes Care. 2007;30(8):2013-8.

104. Fantini MP, Compagni A, Rucci P, et al. General practitioners' adherence to evidence-based guidelines: a multilevel analysis. Health Care Manage Rev. 2012;37(1):67-76.

105. Pham HH, Schrag D, Hargraves JL, et al. Delivery of preventive services to older adults by primary care physicians. JAMA. 2005;294(4):473-81.

106. Dahrouge S, Seale E, Hogg W, et al. A Comprehensive Assessment of Family Physician Gender and Quality of Care: A Cross-Sectional Analysis in Ontario, Canada, Med Care. 2016;54(3):277-86.

107. Ferroni E, Casotto V, Pigato M, et al. Patient and General Practitioner characteristics influencing the management of non-insulin-treated diabetes mellitus: A cross-sectional study in Italy. Diabetes Res Clin Pract. 2016;116:192-201.

108. Kim C, McEwen LN, Gerzoff RB, et al. Is Physician Gender Associated With the Quality of Diabetes Care? Diabetes Care. 2005;28(7): 1594.

109. Streja DA, Rabkin SW. Factors associated with implementation of preventive care measures in patients with diabetes mellitus. Arch Intern Med. 1999;159(3):294-302.

110. Chaitoff A, Rothberg MB, Windover AK, et al. Physician Empathy Is Not Associated with Laboratory Outcomes in Diabetes: a Cross-sectional Study. Journal of General Internal Medicine. 2019;34(1):75-81.

111. Holmboe ES, Wang Y, Tate JP, et al. The effects of patient volume on the quality of diabetic care for Medicare beneficiaries. Med Care 2006;44(12): 1073-7.

112. Turchin A, Shubina M, Pendergrass ML. Relationship of physician volume with process measures and outcomes in diabetes. Diabetes Care. 2007;30(6):1442-7.

113. Mahabaleshwarkar R, Gohs F, Mulder H, et al. Patient and Provider Factors Affecting Clinical Inertia in Patients With Type 2 Diabetes on Metformin Monotherapy. Clinical Therapeutics. 2017;39(8):1658-70.e6.

114. Dahrouge S, Hogg W, Younger J, et al. Primary Care Physician Panel Size and Quality of Care: A Population-Based Study in Ontario, Canada. Ann Fam Med. 2016;14(1):26-33.

115. Mitchell E, McConnahie A, Sullivan F. Consultation computer use to improve management of chronic disease in general practice: a before and after study. Inform Prim Care. 2003;11(2):61-8.

116. Wencui H, Sharman R, Heider A, et al. Impact of electronic diabetes registry 'Meaningful Use' on quality of care and hospital utilization. J Am Med Inform Assoc. 2016;23(2):242-7.

117. Kontopantelis E, Reeves D, Valderas JM, et al. Recorded quality of primary care for patients with diabetes in England before and after the introduction of a financial incentive scheme: a longitudinal observational study. BMJ Quality \& Safety. 2013;22(1):53-64.

118. Franks P, Fiscella K, Beckett L, et al. Effects of patient and physician practice socioeconomic status on the health care of privately insured management care patients. Med Care. 2003;41(7):842-52.

119. Wong $\mathrm{CKH}$, Fung CSC, Kung K, et al. Quality of care and volume for patients with diabetes mellitus in the primary care setting: A population based retrospective cohort study. Diabetes Res Clin Pract. 2016;120:171-81

120. Vamos EP, Pape UJ, Bottle A, et al. Association of practice size and payfor-performance incentives with the quality of diabetes management in primary care. CMAJ. 2011;183(12):E809-16.

121. Everett C, Thorpe C, Palta M, et al. Physician assistants and nurse practitioners perform effective roles on teams caring for Medicare patients with diabetes. Health Affairs (Project Hope). 2013;32(11):1942-8.

122. Kuo Y-F, Goodwin JS, Chen N-W, et al. Diabetes Mellitus Care Provided by Nurse Practitioners vs Primary Care Physicians. J Am Geriatr Soc. 2015;63(10): 1980-8.

123. Faza NN, Akeroyd JM, Ramsey DJ, et al. Effectiveness of NPs and PAs in managing diabetes and cardiovascular disease. JAAPA: Official Journal Of The American Academy Of Physician Assistants. 2018;31(7):39-45.

124. Franks P, Bertakis KD. Physician gender, patient gender, and primary care. J Womens Health (Larchmt). 2003;12(1):73-80.
125. Lurie N, Slater J, McGovern P, et al. Preventive care for women. Does the sex of the physician matter? N Engl J Med. 1993;329(7):478-82.

126. Baumhakel M, Muller U, Bohm M. Influence of gender of physicians and patients on guideline-recommended treatment of chronic heart failure in a cross-sectional study. Eur J Heart Fail. 2009;11(3):299-303.

127. Tsugawa Y, Jena AB, Figueroa JF, et al. Comparison of Hospital Mortality and Readmission Rates for Medicare Patients Treated by Male vs Female Physicians. JAMA internal medicine. 2017;177(2):206-13.

128. Nam S, Chesla C, Stotts NA, et al. Barriers to diabetes management: patient and provider factors. Diabetes Res Clin Pract. 2011;93(1):1-9.

129. Roter DL, Hall JA, Aoki Y. Physician gender effects in medical communication: a meta-analytic review. JAMA. 2002;288(6):756-64

130. Ewing GB, Selassie AW, Lopez CH, et al. Self-report of delivery of clinical preventive services by U.S. physicians. Comparing specialty, gender, age, setting of practice, and area of practice. Am J Prev Med. 1999;17(1):62-72.

131. Henderson JT, Weisman CS. Physician gender effects on preventive screening and counseling: an analysis of male and female patients' health care experiences. Med Care. 2001;39(12):1281-92.

132. Tsugawa Y, Newhouse JP, Zaslavsky AM, et al. Physician age and outcomes in elderly patients in hospital in the US: observational study. BMJ. 2017;357.

133. Christian AH, Mills T, Simpson SL, et al. Quality of cardiovascular disease preventive care and physician/practice characteristics. J Gen Intern Med. 2006;21(3):231-7.

134. Choudhry NK, Fletcher RH, Soumerai SB. Systematic review: The relationship between clinical experience and quality of health care. Ann Intern Med. 2005;142(4):260-73.

135. Goodwin JS, Salameh H, Zhou J, et al. Association of Hospitalist Years of Experience With Mortality in the Hospitalized Medicare Population. JAMA Intern Med. 2018;178(2):196-203.

136. Epstein AJ, Srinivas SK, Nicholson S, et al. Association between physicians' experience after training and maternal obstetrical outcomes: cohort study. BMJ. 2013;346:f1596.

137. Freiman MP. The Rate of Adoption of New Procedures among Physicians: The Impact of Specialty and Practice Characteristics. Med Care. 1985;23(8):939-45.

138. Halm EA, Lee C, Chassin MR. Is volume related to outcome in health care? A systematic review and methodologic critique of the literature. Ann Intern Med. 2002;137(6):511-20.

139. Nguyen YL, Wallace DJ, Yordanov Y, et al. The Volume-Outcome Relationship in Critical Care: A Systematic Review and Meta-analysis. Chest. 2015; 148(1):79-92.

140. O'Neill KN, McHugh SM, Tracey ML, et al. Health service utilization and related costs attributable to diabetes. Diabet Med. 2018.

141. Zghebi SS, Steinke DT, Carr MJ, et al. Examining trends in type 2 diabetes incidence, prevalence and mortality in the UK between 2004 and 2014. Diabetes Obes Metab. 2017;19(11):1537-45.

142. Tamayo T, Rosenbauer J, Wild SH, et al. Diabetes in Europe: An update. Diabetes Res Clin Pract. 2014;103(2):206-17.

143. Nocon A, Rhodes PJ, Wright JP, et al. Specialist general practitioners and diabetes clinics in primary care: a qualitative and descriptive evaluation. Diabet Med. 2004;21(1):32-8.

144. Nocon A, Leese B. The role of UK general practitioners with special clinical interests: implications for policy and service delivery. $\mathrm{Br} \mathrm{J}$ Gen Pract. 2004;54(498):50-6.

145. Jackson C, Tsai J, Brown C, et al. GPs with special interests - impacting on complex diabetes care. Aust Fam Physician. 2010;39(12):972-4.

146. Garcia MC, Faul M, Massetti G, et al. Reducing potentially excess deaths from the five leading causes of death in the rural United States. MMWR Surveillance Summaries. 2017;66(2):1.

147. Cook NL, Hicks LS, O'Malley AJ, et al. Access To Specialty Care And Medical Services In Community Health Centers. Health Aff (Millwood). 2007;26(5):1459-68.

148. Goldman LE, Chu PW, Tran H, et al. Federally Qualified Health Centers and Private Practice Performance on Ambulatory Care Measures. Am J Prev Med. 2012;43(2): 142-9.

149. Zhang JQ, Van Leuven KA, Neidlinger SH. System Barriers Associated With Diabetes Management in Primary Care. The Journal for Nurse Practitioners. 2012;8(10):822-7.

150. Bodenheimer T, Grumbach K. Electronic technology: a spark to revitalize primary care? JAMA. 2003;290(2):259-64.

151. May CR, Johnson M, Finch T. Implementation, context and complexity. Implementation Science. 2016;11(1):141. 
152. Davy C, Bleasel J, Liu H, et al. Factors influencing the implementation of chronic care models: A systematic literature review. BMC Fam Pract. 2015;16:102.

153. Kadu MK, Stolee P. Facilitators and barriers of implementing the chronic care model in primary care: a systematic review. BMC Fam Pract. 2015;16(1): 12

154. Neuwirth EEB, Schmittdiel JA, Tallman K, et al. Understanding panel management: a comparative study of an emerging approach to population care. The Permanente journal. 2007;11(3):12-20.

155. Laurant M, van der Biezen M, Wijers N, et al. Nurses as substitutes for doctors in primary care. Cochrane Database Syst Rev. 2018;7:Cd001271.

156. Zhang J, Burridge L, Baxter KA, et al. A new model of integrated primary-secondary care for complex diabetes in the community: study protocol for a randomised controlled trial. Trials 2013;14:382.

157. Elrashidi MY, Mohammed K, Bora PR, et al. Co-located specialty care within primary care practice settings: A systematic review and metaanalysis. Healthcare 2018;6(1):52-66.

158. Russell AW, Baxter KA, Askew DA, et al. Model of care for the management of complex Type 2 diabetes managed in the community by primary care physicians with specialist support: an open controlled trial. Diabet Med. 2013;30(9):1112-21.

159. Riordan F, McHugh SM, N. M, et al. 'Sink or Swim'. Adapting to support the delivery of integrated diabetes care: experiences of clinical nurse specialists. Int J Integrated Care. 2019;19(2):2. https://doi.org/10. $5334 /$ ijic. 4215

160. Johnson M, Goyder E. Changing roles, changing responsibilities and changing relationships: an exploration of the impact of a new model for delivering integrated diabetes care in general practice. Qual Prim Care. 2005;13(2):85-90 6p.

161. Walsh JL, Harris BH, Roberts AW. Evaluation of a community diabetes initiative: Integrating diabetes care. Prim Care Diabetes. 2015;9(3):20310.
162. Gruen R, Weeramanthri T, Knight S, et al. Specialist outreach clinics in primary care and rural hospital settings (Cochrane Review). Community Eye Health. 2006;19(58):31.

163. Gruen RL, Weeramanthri TS, Knight SS, et al. Specialist outreach clinics in primary care and rural hospital settings. Cochrane Database of Systematic Reviews. 2003(4).

164. Coleman K, Austin BT, Brach C, et al. Evidence on the Chronic Care Model in the new millennium. Health Aff (Millwood). 2009;28(1):75-85.

165. Heisler M, Bouknight RR, Hayward RA, et al. The relative importance of physician communication, participatory decision making, and patient understanding in diabetes self-management. J Gen Intern Med. 2002; 17(4):243-52.

166. Garg AX, Adhikari NK, McDonald H, et al. Effects of computerized clinical decision support systems on practitioner performance and patient outcomes: a systematic review. JAMA. 2005;293(10):1223-38.

167. Ng CW, Ng KP. Does practice size matter? Review of effects on quality of care in primary care. Br J Gen Pract. 2013;63(614):e604-10.

168. Institute of Medicine (US) Committee on Quality of Health Care in America. Crossing the Quality Chasm: A New Health System for the 21st Century. Washington (DC): National Academies Press (US) 2001.

169. Institute of Medicine Committee on the Work Environment for Nurses and Patient Safety. In: Page A, editor. Keeping Patients Safe: Transforming the Work Environment of Nurses. Washington (DC): National Academies Press (US) Copyright 2004 by the National Academy of Sciences. All rights reserved.; 2004

Publisher's Note: Springer Nature remains neutral with regard to jurisdictional claims in published maps and institutional affiliations. 